\title{
Autonomia do paciente com doença renal crônica em
tratamento hemodialítico: a aceitação como fator decisório*
}

\author{
Autonomy of patients with chronic renal disease on hemodialysis: acceptance as a decisive factor for \\ compliance with the treatment
}

\begin{abstract}
Autonomía del paciente con enfermedad renal crónica en tratamiento de bemodiálisis: la aceptación como factor decisivo
\end{abstract}

\author{
Elizete Sampaio Araujo ${ }^{1}$, Luciane Lucio Pereira ${ }^{2}$, Marcio Fabri dos Anjos ${ }^{3}$
}

\begin{abstract}
RESUMO
Objetivo: Analisar a autonomia vivenciada pelo paciente portador de doença renal crônica em tratamento hemodialítico. Métodos: Pesquisa descritiva, exploratória, de abordagem qualitativa, desenvolvida em uma clínica satélite, localizada na Grande São Paulo-SP. Foram entrevistados 11 pacientes em tratamento hemodialítico. O referencial metodológico apoiado em Bardin, foi a análise de conteúdo e surgiu a categoria aceitação com suas subcategorias: obediência e conformação. Resultados: Segundo relatos, a obediência ao tratamento significa a manutenção da vida. A aceitação do tratamento hemodiálitico parece ser uma questão de conformação que se relaciona, em especial, com o fato do paciente sentir-se sem opções de escolhas referentes à terapêutica. Conclusão: A aceitação como processo de obediência e conformação apresenta-se como a única opção para a sobrevivência do portador dessa doença. É importante que o paciente conheça sua doença e a terapêutica ofertada, pois, assim poderá se fazer sujeito em seu tratamento, exercendo sua autonomia, apesar de sua fragilidade. Descritores: Autonomia pessoal; Diálise renal; Insuficiência renal crônica
\end{abstract}

\begin{abstract}
Objective: To describe the autonomy of patients with chronic renal disease on hemodialysis. Methods: A qualitative, descriptive, and exploratory study was conducted with 11 patients on hemodialysis from a satellite clinic in the Great São Paulo. Data were collected through interviews. Bardin's methodological framework guided the content analysis of the data. Results: Acceptance emerged as the main theme. Compliance and conformation were classified as subthemes of acceptance. Acceptance of hemodialysis was seen as conformation and it is related to the decision-making process in choosing to comply or not with the treatment. The meaning of compliance with hemodialysis was viewed as maintenance of life. Conclusion: Acceptance as a form of compliance and conformation is the only option that guarantees the survival of patients with chronic renal disease. It is important that the patients with chronic renal disease acquire knowledge about the disease and its treatment to have autonomy for decision-making regarding hemodialysis.
\end{abstract}

Keywords: Personal autonomy; Renal dialysis; Renal insufficiency, chronic

\section{RESUMEN}

Objetivo: Analizar la autonomía vivenciada por el paciente portador de una enfermedad renal crónica con tratamiento de hemodiálisis. Métodos: Se trata de una investigación descriptiva, exploratoria, con abordaje cualitativo, desarrollado en una clínica satélite, localizada en la Grande Sao Paulo-SP. Fueron entrevistados 11 pacientes con tratamiento de hemodiálisis. El referencial metodológico fundamentado en Bardin, fue el análisis de contenido de la cual surgió la categoría aceptación con sus subcategorías: obediencia y conformación. Resultados: De acuerdo a los relatos, la obediencia al tratamiento significa la manutención de la vida. La aceptación del tratamiento de hemodiálisis parece ser una cuestión de conformación que se relaciona, de manera especial, con el hecho de que el paciente se sienta sin opciones de elección en cuanto a la terapéutica. Conclusión: La aceptación como proceso de obediencia y conformación se presenta como la única opción para la sobrevivencia del portador de esa enfermedad. Es importante que el paciente conozca su enfermedad y la terapéutica ofrecida, pues, así podrá hacerse sujeto en su tratamiento, ejerciendo su autonomía, pese a su fragilidad.

Descriptores: Autonomía personal; Diálisis renal; Insuficiencia renal crónica

\footnotetext{
* Estudo desenvolvido em uma clínica satélite, localizada na Grande São Paulo (SP), Brasil.

${ }^{1}$ Mestre em Bioética, Professora de Enfermagem do Centro Universitário São Camilo e Universidade Paulista - UNIP - São Paulo (SP), Brasil; Responsável

Técnica pelo Serviço de Nefrologia da Lapa - Hospital Sorocabana - São Paulo (SP), Brasil.

${ }^{2}$ Doutora em Enfermagem, Pró-Reitora Acadêmica do Centro Universitário São Camilo - São Paulo (SP), Brasil.

${ }^{3}$ Filósofo, Doutor em Teologia pela Pontifícia Universidade Gregoriana, Roma, Itália. Diretor do Instituto Alfonsianum de Ética Teológica. Pesquisador e docente do Centro Universitário São Camilo, São Paulo (SP), Brasil.
} 


\section{INTRODUÇÃO}

Minhas primeiras experiências profissionais como enfermeira ocorreram em unidades de nefrologia e, até hoje, constituem minha área de atuação.

$\mathrm{Na}$ pratica profissional, observo que os pacientes em terapia hemodialítica apresentam uma sobrevida de quase 15 anos o que requer uma adequada abordagem pela equipe de enfermagem a fim de orientar os pacientes sobre a adesão ao tratamento, a qualidade de vida, o entendimento da situação vivida e a escolha da terapia dialítica.

Observo que os pacientes que precisam de hemodiálise por longo prazo, relatam que permanecem preocupados com a imprevisibilidade da doença e com a ruptura da rotina de suas vidas, já que esse tratamento impõe um estilo de vida disciplinado e regulamentado pela terapia.

Desse modo, prestar assistência de enfermagem individualizada, atendendo as necessidades dos pacientes e garantindo a qualidade e o respeito sempre foram meus ideais e nortearam as ações que desenvolvo, pois necessitamos de profissionais preocupados com o ser humano. Assim, busco desenvolver meios para oferecer uma assistência de enfermagem que valorize uma existência digna e um diálogo compreensivo com os pacientes.

Assim, o objetivo deste estudo foi o de analisar a autonomia vivenciada pelo paciente portador de doença renal crônica em tratamento hemodialítico.

\section{Revisão de literatura}

A doença renal crônica (DRC) é vista como uma pandemia do século XXI e é avaliada pela Sociedade Brasileira de Nefrologia (SBN) como uma "nova epidemia negligenciada da modernidade". Calcula-se que existam dois milhões de brasileiros portadores de algum grau de disfunção renal, com risco dez vezes maior de morrer prematuramente por doença cardiovascular em relação à população normal. No entanto, cerca de $70 \%$ destas pessoas desconhecem o diagnóstico. Segundo dados da International Society of Nephrology, até 2015, 36 milhões de pessoas morrerão de doença renal no mundo ${ }^{(1)}$.

Os principais fatores de risco para desenvolver DRC são: diabetes mellitus, hipertensão arterial, envelhecimento e história familiar de DRC. Independentes do diagnóstico etiológico da DRC, a presença de dislipidemias, obesidade e tabagismo podem acelerar o curso da doença.

Há possibilidade de intervenção no curso da doença renal por meio de melhoria da atenção à saúde em todos os níveis de atendimento a indivíduos portadores dos fatores de risco para a DRC.

O Ministério da Saúde divulgou dados que mostram que entre indivíduos acima de 40 anos, há cerca de 17 milhões de hipertensos e 5 milhões de diabéticos, sendo $90 \%$ do tipo 2. Como a população brasileira vem envelhecendo gradativamente, observa-se que a obesidade e o sedentarismo vêm crescendo de forma assustadora entre a população mundial ${ }^{(2)}$.

As doenças crônicas são de longa duração, apesar dos avanços científicos e tecnológicos, muitas vezes, são consideradas incuráveis, como a DRC. Conforme dados divulgados pela SBN, no censo de 2006, no Brasil, havia cerca de 70.000 pacientes em terapia dialítica e 175 casos novos por milhão de habitantes diagnosticados por ano, prevalência de 383 pacientes por milhão da população e com base no crescente número de indivíduos pertencentes aos grupos de risco para DRC. Assim, estima-se que este número possa duplicar nos próximos cinco anos, ultrapassando os 125 mil casos em $2010^{(3)}$.

Nos últimos oito anos a prevalência de pacientes mantidos em hemodiálise no Brasil mais que dobrou. Em 1994, havia 24.000 pacientes mantidos em programa dialítico, em 2004, foram registrados 59.153, e, em 2006, 70.872. Os dados indicam crescimento de $9 \%$ ao ano na incidência de novos pacientes, e, em 2001, foram 18.000, em 2005, 32329 (3-4).

Hoje, a SBN divulga dados que revelam a existência de, aproximadamente, 73.605 pacientes no Brasil que realizam terapia dialítica, correspondendo a uma prevalência de 3,9 pacientes por milhão de habitantes ${ }^{(3)}$.

Um autor em estudo realizado, comparou, gastos com saúde no Brasil e em outros paises, “[...] o Brasil é um dos paises com o menor gasto per capita em saúde: 100 reais por pessoa ano. Os gastos em saúde, convertidos em reais de alguns paises: Uruguai, $\mathrm{R} \$ 400$; Argentina, $\mathrm{R} \$$ 600; Canadá, R \$ 2.000; Estados Unidos, R\$ 4.000”(5).

A DRC é diagnosticada tardiamente, pois o indivíduo portador segue assintomático durante anos, em razão dos rins apresentarem a capacidade de manter sua função com até $10 \%$ ou menos de seu parênquima renal funcionante, pois os néfrons remanescentes são capazes de se adaptarem à nova condição biológica multiplicando em várias vezes seu ritmo de trabalho.

No estudo com a população de Bambuí - MG, foi concluido que a projeção de disfunção renal na população brasileira seria de aproximadamente 1,4 milhões de pessoas. Sabe-se que os portadores de disfunção renal leve apresentam quase sempre uma evolução lenta, progressiva, assintomática e insidiosa, o que dificulta o diagnóstico precoce ${ }^{(4)}$.

Dados norte-americanos demonstram que, para cada indivíduo mantido em programa de diálise crônica, existiriam cerca de 20 a 25 pacientes com algum grau de disfunção renal, ou seja, 1,2 a 1,5 milhão de indivíduos com DRC ${ }^{(4,6)}$.

Ainda,em estudo realizado com 332.500 homens, o autor observou que o risco de desenvolvimento de nefropatia diabética é de cerca de 30\% nos diabéticos tipo 1 e de $20 \%$ nos diabéticos tipo 2 , e que a incidência 
de DRC em pacientes hipertensos é de cerca de 156 casos por milhão de pessoas ${ }^{(4)}$.

\section{MÉTODOS}

Trata-se de uma pesquisa descritiva, exploratória, qualitativa que se apoiou na analise de conteúdo de Bardin.

A pesquisa foi desenvolvida na Unidade Satélite, localizada na Grande São Paulo. Optou-se por este serviço de hemodiálise, por prestar assistência à saúde vinculada ao Sistema Único de Saúde (SUS) atendendo à Resolução da Diretoria Colegiada da Agência Nacional de Vigilância Sanitária, no 154/2004 do Ministério da Saúde e por disponibilizar somente terapia hemodialítica aos pacientes cadastrados pelo SUS.

O projeto deste estudo foi aprovado pelo Comitê de Ética em Pesquisa do Centro Universitário São Camilo.

Os 11 sujeitos da pesquisa eram pacientes portadores de DRC, realizando terapia hemodialítica, a qualquer tempo, com recursos financeiros governamentais, maiores de 18 anos e que aceitaram participar do estudo, após receberem os esclarecimentos de seus objetivos, serem informados da segurança do anonimato da participação e assinarem o Termo de Consentimento Livre e Esclarecido.

Os procedimentos da coleta dos dados basearam-se em uma entrevista, com o uso de um roteiro, contendo uma parte da caracterização do sujeito da pesquisa, com informações referentes ao sexo, idade, tempo de tratamento, escolaridade e religião e outra composta por questões norteadoras que possibilitaram o alcance dos objetivos propostos.

As questões norteadoras foram:

1. Você foi esclarecido (a) sobre sua doença e/ou tratamento?

2. Como foi sua participação na escolha da terapia hemodialítica?

3. Como você se sente realizando a terapia hemodialitica?

4. Em que a DRC e a terapia hemodialitica influenciam sua vida?

5. Tem algo mais que você gostaria de dizer?

As entrevistas gravadas foram transcritas para a realização da análise do conteúdo, conforme sugerida por Bardin e descrita a seguir:

A análise de conteúdo pode ser entendida como um conjunto de técnicas de análise das comunicações visando obter, por procedimentos, sistemáticos e objetivos de descrição do conteúdo das mensagens, indicadores (quantitativos ou não) que permitam a inferência de conhecimentos relativos às condições de produção / recepção (variáveis inferidas) destas mensagens ${ }^{(7)}$.

O roteiro foi validado após a realização do pré-teste, em que foram realizadas as adequações necessárias relativas às perguntas norteadoras.

\section{RESULTADOS}

A amostra do público alvo constituíu-se de 11 pacientes: sete do sexo feminino e quatro do sexo masculino; com idades entre 33 e 76 anos, nível de escolaridade entre primeiro ciclo do Ensino Fundamental incompleto e nível universitário. No que se refere à prática religiosa, apenas um referiu não ter uma religião definida. Quatro entrevistados mencionaram ser diabéticos, três hipertensos, um ter doença policística e quatro não sabiam informar a doença de base. A renda financeira compreendeu entre menos de um salário a três salários minimos/mês.

A categoria aceitação refere-se à análise do modo de como o paciente vivencia a realização do tratamento, independente da compreensão sobre o processo saúdedoença. A aceitação pelo tratamento, na maior parte dos relatos, parece ser uma questão de conformação ou obediência e não propriamente de esclarecimento e/ou reconhecimento do processo de tratamento. Nesta categoria, foram identificadas duas subcategorias: obediência e conformação.

A maior parte dos sujeitos relatou a necessidade de realizar o tratamento, mesmo sem a compreensão do processo. Expressaram que o tempo é um fator determinante para a aceitação da enfermidade. Sendo indicado como necessário para lidarem com a realidade de serem dependentes da "máquina".

Para melhor compreender o processo de aceitação da DRC, nesses pacientes, é preciso analisar as subcategorias: obediência e conformação. Por obediência entende-se o processo de submissão à autoridade da equipe de saúde e, por conformação, o movimento de aceitação da doença de modo resignado, uma aceitação sem contestação.

Embora se observe que o limite entre essas duas subcategorias seja muito tênue, será definido como: no item obediência, são as demonstrações de cumprimento ao tratamento, relacionadas com os fatores de modalidade terapêutica, de orientação nutricional e de influências familiares. Na questão de conformação é de interesse discutir as manifestações referentes à forma resignada como os sujeitos da pesquisa acatavam as orientações terapêuticas. em ambas situações o elo é o da escolha pelo tratamento.

\section{Subcategoria I: Obediência}

Esta subcategoria procura retratar como os sujeitos do estudo seguiram as orientações recebidas dos profissionais de saúde, acreditando serem as únicas capazes de os manterem vivos. Demonstraram realizar o tratamento mesmo sem compreenderem o procedimento, ou seja, apenas acatando as orientações da equipe de saúde. Alguns relatos expressam a obediência relacionada à indicação da modalidade do tratamento. 
“(...) HD é a única solução que o senhor vai conseguir sobreviver, porque o senhor faz hemodiálise dia sim dia não e cada dia que você faz é um dia a mais, porque sem hemodiálise o senhor não vai sobreviver, até você entrar na fila de transplante. Ai eu não teria outro jeito, tudo bem e então enfrentei, tudo bem (...) porque o médico falou pra mim, é a única solução que o senhor tem, pra fazer $H D$, porque não é que o senhor vai sarar mais, o senhor vai ter um dia a mais de vida, porque o senhor vai passar a fazer 3 dias por semana, porque não tinha mais pra onde eu ir. (...) Porque daqui a 3 meses o senhor vai morrer inchado e o coração não vai mais transmitir sangue pro coração, ai... eu não tinha mais saída. Eu não tinha como ter saída mais. Se você mexe com esta pratica aí, você sabe que a saída não existe, e assim mesmo nós fazendo $H D$, isso é minha opinião pessoal ..."(E3)

A ênfase deste paciente, na questão da obediência, sugere a compreensão de que se ele cumprir as determinações prescritas pelo médico, aumentariam as possibilidades de resultados satisfatórios e, assim, suas chances de sobrevivência. Nesse sentido, entende-se que o sujeito assume também a responsabilidade por sua terapêutica.

Em outras situações, ainda no que se refere ao cumprimento do tratamento, é comum os sujeitos pesquisados indicarem ser esta a única alternativa para a manutenção da vida.

"Hoje ... que já faz quase 7 anos, tudo ... eu me sinto muito bem ... aceito o tratamento e ... reconbeço que poderia ... ser pior se não tivesse tido a chance, né? ... e enfim todos os dias eu me sinto bem, né?" (E6)

"É... não, na época o único tratamento que tinha seria a HD, somente. De qualquer jeito eu tinha que fazer porque, uma que en não urinava mais, era só a máquina que era pra tirar(...)”. (E4)

"Eu tenho que fazer diálise, se eu não fizer ... eu tenho que fazer eu não tenho opção, entendeu? Isto ai épelo resto de minha vida. Eu sei que não pode parar, eu sei que se eu resolverparar, ai já era né? e quando eu falo já era eu quero dizer é morrer mesmo né, e vai mesmo. Então você é obrigada a fazer". (E10)

“(...) ou en faria o tratamento ou eu morria..."(E5)

“(...) você tem que fazer, não tem outro jeito, porque a diálise é você que sente. Se você não... optar por não fazeer, não quer ir lá fazer, você morre né...” (E11)

Nos depoimentos, outro enfoque observado foi à necessidade de obediência quanto à indicação da dieta nutricional, fator decisivo para melhor qualidade de vida do paciente.

"(...) ai eles me orientaram que não era pra eu beber muito líquido, água. Que eu tinha que tomar $800 \mathrm{ml}$ por dia inclusive a nutricionista, ela desenvolveu uma cartilha do que en poderia fazere não podia. Ai eu comecei a seguir as regras direitinho". (E4)

Percebe-se que a obediência no tratamento significa, segundo os relatos, a manutenção da vida. Vida que pode ser mantida através do processo hemodialítico, das restrições dietéticas e do papel da família, como fim e/ ou como meio, para a decisão do portador de DRC ao cumprimento da terapêutica.

\section{Subcategoria II: Conformação}

Esta subcategoria, no âmbito da categoria de aceitação, procura demonstrar pelos relatos dos sujeitos da pesquisa, que a aceitação ao tratamento hemodialítico parece ser uma questão de conformação e não propriamente de esclarecimento e de reconhecimento do processo.

De modo geral, os pacientes entrevistados citaram o sentimento de que "têm uma vida normal", para eles, isto significa que a realização do tratamento não impõe restrições maiores ao modo de vida. No entanto, isso parece uma contradição, pela constante queixa em relação às restrições de diferentes naturezas, que o tratamento impõe; pode também ser interpretado como uma maneira de se conformar, no sentido de se ajustar e se resignar à nova condição de vida.

Em seus depoimentos, os sujeitos pesquisados demonstraram reconhecer o fato de que poderiam ter uma qualidade de vida pior, caso não existisse $o$ tratamento. Relataram que uma pessoa, com problema renal, não sobreviveria sem esta terapêutica. Nesse sentido, aceitam realizá-la mesmo sem saber quais os procedimentos e conseqüências envolvidas. O padrão de normalidade é dado pela nova condição de vida.

Portanto, pode-se entender que, uma vida normal, como eles expressaram, relaciona-se com o fato de estar vivo.

Essa compreensão não é imediata, como ilustram as falas a seguir:

"Então, ... mas vai acabando entristecendo um pouco, mas o tempo faz a gente aceitar e adaptar a vida do jeito que dá pra ser né?(...) Aí depois eu fui me acalmando, aceitando melhor a idéia". (E6)

“(...) Quando ela me deu a noticia, pra quem não tá preparado pra essa surpresa, é dificil aceitar assim aceitar de imediato, é muito difícil, muito mesmo. Depois de uma semana men filho me levou de volta e eu comecei a fazer o tratamento e eu comecei a aceitar, en vivo melhor, enquanto você não aceita, você vive muito mal e isso não é bom, graças a Deus que eu aceitei”. (E2)

"Ih demorou pra eu entender mas agora eu levo numa boa sabe, porque eu sei que não tem jeito mesmo, se não fazer passa mal, então tem que fazer mesmo né?. Sabe, chorava muito, ficava desesperada, não me conformava, estar nesta máquina aqui, sabia que tinha que fazer né?(E1)

As verbalizações desses pacientes remetem para a necessidade de compreender que o tempo e as informações atuam como fatores predisponentes para que o portador de DRC se perceba, não apenas como sujeito em tratamento, mas sujeito do seu tratamento. 
Outro fator a ser considerado é a conformação, é o sofrimento durante a realização do tratamento. Uma paciente expressou como o sofrimento atua como componente para a conformação com a doença:

"Ah, en acho que influencion muita coisa, porque acho que o sofrimento amadurece a gente, é muito sofrimento a hemodiálise é... porque não é fácil de faz̧er e dizer que você faz. e não sente nada e se pensar... não é fácil... eu não reclamo disso, eu mudei muito, assim... mudei, porque é muito sofrimento... Só isso". (E2)

A conformação à doença solicita a intervenção da equipe multidisciplinar, tornando-se imprescindível a participação de profissionais do campo da psicologia e da assistência social, para o entendimento do processo de saúde-doença, sentimento ilustrado pelos pacientes:

“(...) mas só que ... as coisas mudam né ... tem que analisar, pensar, comecei a trabalhar com a psicóloga, e ... me ajudou muito, a Doutora XXX me ajudou muito, me ajuda até hoje, inclusive vou fazer esse documentário porque ... e comecei a ver a vida diferente, $e$ comecei a tomar certas atitudes ... diferentes em relação ao tipo da doença e comecei a procurar também o significado de cada, de cada, (....) do que eu sentia, dos problemas que dava e... ih ... que eu tinha condições de viver e... de ter condições de ter uma chance de sair desta máquina, né?" (E5)

Em termos de aceitação da doença, a conformação aparece como uma característica que se desenvolve ao longo do tratamento. As informações prestadas no início da terapia, ainda que reconhecidas por um paciente como de boa qualidade, não implicam, necessariamente, em compreensão e aceitação da enfermidade em seus aspectos fisiopatológicos. Conforme o declarado por um paciente, a experiência é fundamental para a aceitação da DRC e de seu tratamento:

“(...) o médico que me encaminhou pra aqui me explicou bem né? Aqui também me explicaram muito bem, mas eu não aceitava, né (...) Ah, eu me sinto bem, né? Apesar dos sintomas que aparecem, mas eu me sinto bem né? Se estou aqui até agora é por causa da diálise né? Gostei. Quer dizer, não vou dižer que gostei, gostei porque dá muitas ... assim, a gente tem muitas reações, né, mas tem que ter né? "(E10)

No processo de aceitação, a conformação relacionase, em especial, com o fato de o paciente sentir-se sem opções de escolhas. Foi recorrente em diversos discursos a argumentação de que a participação na escolha e aceitação do tratamento não se apresentava como algo efetivamente possível, ou seja, diante da DRC, a alternativa que se apresenta ao paciente é a escolha entre a vida e a morte. Nesse sentido, todos os sujeitos pesquisados optaram pela vida. A escolha refere-se à condição de realização do tratamento.

\section{DISCUSSÃO}

Os depoimentos, apresentados, remetem ao questionamento de que, quando a escolha é a própria vida, não há escolha.

O paciente tem direito incondicional a toda informação relativa à sua saúde, tratamento e às alternativas disponíveis. A ele, é delegado o mesmo direito, igualmente absoluto, de rejeitar o tratamento, porém; essa rejeição significa rejeitar a própria vida ${ }^{(8)}$.

Essa questão também é tratada por outro autor que a identifica com o aspecto da vulnerabilidade do sujeito em tratamento. Em outras palavras, isso significa considerar que a obediência do paciente à terapêutica encontra-se fortemente marcada pelos limites de sua autonomia ${ }^{(9)}$.

Todas essas falas expressam o entendimento de que a obrigatoriedade do cumprimento das orientações nutricionais configura-se como fator decisivo no sucesso da terapêutica hemodialítica e, ao mesmo tempo, apontam ser esta uma das maiores dificuldades a serem superadas.

A obediência ao tratamento significa, segundo os relatos, a manutenção da vida. Vida que pode ser mantida através do processo hemodialítico, das restrições dietéticas e do papel da família, como fim e/ou como meio, para a decisão do portador de DRC ao cumprimento da terapêutica.

Para este autor, a obediência, nesse sentido, pode ser interpretada como uma maneira de o paciente exercer sua autonomia, relembrando que para existir a liberdade de decidir é indispensável que existam alternativas ou a possibilidade de se criarem as mesmas ${ }^{(4)}$.

Outro autor pondera que, o "reconhecimento da própria vulnerabilidade é ponto de partida para uma construção maior. Possibilita o encontro construtivo com o outro e os passos de superação das próprias fragilidades". Quando o paciente interpreta as condições de vida como não tendo outra escolha, ele aceita sua fragilidade humana e conforma-se com a nova condição de vida ${ }^{(9)}$.

Os discursos remetem à importância do consentimento esclarecido, da seriedade da informação e da condição da fragilidade humana, fatos corroborados por estes autores, que preconizam que, quando consentese que um paciente desempenhe sua autonomia, caracterizada por autodeterminação, respeitando sua capacidade de fazer as próprias escolhas e de governar as próprias ações sem coações, está se respeitando o agir segundo a sua própria vontade. Porém, convém lembrar que o agir segundo sua própria vontade dá-se em um cenário marcado pela vulnerabilidade ${ }^{(10)}$.

\section{CONCLUSÃO}

De modo geral, podemos afirmar que a aceitação, 
como processo de obediência e de conformação ao tratamento hemodialítico apresenta-se como a única opção para a sobrevivência do portador de DRC. Assim, pode ser compreendida como um modo de enfrentamento da doença. Esta condição o capacita para enfrentar a vida.

O tempo mostrou-se como fator determinante para aceitação da doença, sendo, inclusive, indicado como necessário para aceitar a realidade de serem dependentes

\section{REFERÊNCIAS}

1. Sociedade Brasileira de Nefrologia (SBN). Previnase.[Internet]. [citado 2007 Mar 18]. Disponível em: http:/ /www.sbn.org.br.

2. Brasil. Ministério da Saúde. Secretaria de Atenção à Saúde. Hiperdia. Sistema de Cadastramento e Acompanhamento de Hipertensos e Diabéticos.[Internet]. [citado 2007 Mar 18]. Disponível em: http://www.hiperdia.datasus.gov.br

3. Sociedade Brasileira de Nefrologia (SBN). Censo 2006/2007. .[Internet]. [citado 2007 Mar 18].Disponível em: http:// www.sbn.org.br/Censo/2007/censo_SBN_2007.ppt\#2

4. Pessini L, Barchifontaine CP. Problemas atuais de bioética. 7a. ed. rev. e ampl. São Paulo: Centro Universitário São Camilo: Edições Loyola; 2005.

5. Romão Júnior JE. Doença renal crônica: definição, da terapêutica, da "máquina dialisadora".

Nesse processo de aceitação, os sujeitos da pesquisa demonstraram não exercerem plenamente a autonomia e relataram grandes perdas e limitações impostas pela terapêutica. Desse modo, é importante que o paciente conheça sua doença e a terapêutica ofertada, pois ao compreender sua enfermidade e terapêutica, poderá se fazer sujeito em/de seu tratamento, exercendo, assim, sua autonomia, apesar de sua fragilidade.

epidemiologia e classificação. J Bras Nefrol. 2004;26(3 Supl 1):1-3.

6. Coresh J, Astor BC, Greene T, Eknoyan G, Levey AS. Prevalence of chronic kidney disease and decreased kidney function in the adult US population: Third National Health and Nutrition Examination Survey. Am J Kidney Dis. 2003;41(1):1-12.

7. Bardin L. Análise de conteúdo. Lisboa: Edições 70; 2006.

8. Pessini L. Como lidar com o paciente em fase terminal. $5 \mathrm{a}$ ed. São Paulo: Edições Loyola; 2003.

9. Anjos MF. A vulnerabilidade como parceira da autonomia. Rev Bras Bioética. 2006;2(2):173-86.

10. Beauchamp TL, Childress JF. Princípios de ética biomédica. São Paulo: Edições Loyola; 2002. 